\title{
Stroke Prevention: Little-Known and Neglected Aspects
}

\author{
M. Reza Azarpazhooh ${ }^{\mathrm{a}}$ Chrysi Bogiatzi ${ }^{\mathrm{b}} \quad$ J. David Spence ${ }^{\mathrm{c}}$ \\ ${ }^{a}$ Division of Neurology and Department of Epidemiology \& Biostatistics, Western University, London, ON, Canada; \\ ${ }^{b}$ Department of Neurology, McMaster University, Hamilton, ON, Canada; 'Stroke Prevention \& Atherosclerosis \\ Research Center, Robarts Research Institute, Western University, London, ON, Canada
}

\section{Keywords}

Stroke prevention - Nutrition · Smoking cessation · Lipid lowering · Insulin resistance · Prediabetes · Antiplatelet therapy · Anticoagulation · Carotid endarterectomy . Carotid stenting

\begin{abstract}
Combining available therapies has the potential to reduce the risk of stroke by $80 \%$ or more. A comprehensive review of all aspects of stroke prevention would be very lengthy; in this narrative review, we focus on some aspects of stroke prevention that are little-known and/or neglected. These include the following: (1) implementation of a Mediterranean diet; (2) B vitamins to lower homocysteine; (3) coordinated approaches to smoking cessation; (4) intensive lipid-lowering therapy; (5) lipid lowering in the elderly; (6) physiologically individualized therapy for hypertension based on renin/aldosterone phenotyping; (7) avoiding excessive blood pressure reduction in patients with stiff arteries; (8) treatment of insulin resistance with pioglitazone in stroke patients with prediabetes and diabetes; (9) impaired activation of clopidogrel in patients with variants of CYP2C19; (10) aspirin pseudoresistance due to enteric coating; $(11)$ rationale for anticoagulation in patients with embolic stroke of unknown source; (12) pharmacologic properties of direct-act-
\end{abstract}

ing oral anticoagulants that should be considered when choosing among them; (13) the identification of which patients with asymptomatic carotid stenosis are at a high enough risk to benefit from carotid endarterectomy or stenting; and (14) the importance of age in choosing between endarterectomy and stenting. Stroke prevention could be improved by better recognition of these issues and by implementation of the principles derived from them.

(c) 2021 S. Karger AG, Basel

\section{Introduction}

It is likely that $80 \%$ or more of strokes could be prevented by a combination [1] of lifestyle modification, effective blood pressure control, antiplatelet or anticoagulant therapy as appropriate, lipid lowering, B vitamins to lower homocysteine, and judicious intervention with endarterectomy or stenting. A comprehensive review of all those topics would be very lengthy; in this narrative review, we focus on some aspects of stroke prevention that are less well known than they ought to be and often neglected. These include selected issues in lifestyle modification, nutrition, blood pressure control, lipid-lowering therapy, hypertension, diabetes, antiplatelet therapy, anticoagulation, and intervention for carotid stenosis. We 
have not emphasized a distinction between primary and secondary prevention because any intervention is more effective (i.e., the number needed to treat [NNT] is lower) in patients at higher risk. An intervention that reduces stroke in primary prevention would be expected to have an even greater effect in secondary prevention.

\section{Lifestyle}

Lifestyle is far more important than most physicians suppose and tends to be neglected in comparison to a focus on medical and surgical management. In a study of health professionals who were healthy at baseline, among 43,685 men and 71,243 women, half of stroke was attributable to an unhealthy lifestyle [2]. Participants who achieved all 5 health lifestyle attributes (not smoking, moderate alcohol intake, a body mass index $<25$, daily exercise for $30 \mathrm{~min}$ and a diet in the top $40 \%$ of a healthy diet score) had an $80 \%$ reduction of ischemic stroke compared to the group with the worst lifestyle attributes. Similarly, myocardial infarction among men was markedly reduced by a healthy lifestyle [3]. Among Swedish women, those with all 5 healthy lifestyle factors had a reduction of ischemic stroke by $62 \%$ compared to no healthy factors [4]. Among Swedish men with hypertension and hyperlipidemia, those with all 5 healthy lifestyle attributes had an $86 \%$ reduction in myocardial infarction versus those with none [5].

\section{Nutrition}

Diet

Although it is possible that vegetarian or pesco-vegetarian diets [6] may be even better, the best evidence for stroke prevention is with the Cretan Mediterranean diet [7]. It is high in whole grains, fruits, vegetables, legumes, nuts, and olive oil or Canola oil and low in meat and dairy products. Keys, the leader of the 7 countries study in which the benefits of the diet were discovered, described it as a "mainly vegetarian" diet [8]. It is a high-fat diet, with $40 \%$ of calories from fat, but it is plant-derived fat, with $1 / 15$ th the coronary risk of the diet in Finland, in which $38 \%$ of calories were from fat, mainly animal fat, accompanied by its evil companion, cholesterol [9]. As a high-fat diet, the Mediterranean diet is a low-glycemic diet; in an Israeli study, it was clearly better for diabetes than either a low-fat diet or a low-carbohydrate diet [10]. Probably the benefits of the Mediterranean diet relate to substitution of olive oil for animal fat and a high intake of fiber, bioflavonoids, and antioxidants.
In secondary prevention, in the Lyon Diet Heart study, a Mediterranean diet reduced stroke and recurrent myocardial infarction by $>60 \%$ in 4 years compared to a "prudent Western diet" resembling a low-fat diet [11]. This was twice the effect of simvastatin in the contemporaneous Scandinavian Simvastatin Survival Study, which reported a $40 \%$ reduction of recurrent myocardial infarction over 6 years [12]. In primary prevention, among participants with risk factors for vascular disease, the Mediterranean diet fortified with nuts reduced stroke by $46 \%$ in 5 years, compared to a low-fat diet [13].

Consumption of cholesterol and eggs increases cardiovascular risk in a dose-dependent manner [14]. Besides the high cholesterol content of eggs and meat, an important advance has been the understanding that toxic metabolic products of the intestinal microbiome are important in cardiovascular disease. Trimethylamine-N-oxide, produced largely from egg yolk and red meat, increases cardiovascular risk [15]. Other toxic metabolites, such as p-cresylsulfate, indoxyl sulfate, hippuric acid, $p$-cresyl glucuronide, pheny acetyl glutamine, and phenyl sulfate are produced from amino acids in dietary protein. Both trimethylamine$\mathrm{N}$-oxide and $p$-cresylsulfate were independent predictors of carotid plaque burden in linear regression [16], and plasma levels of all 7 toxic metabolites measured in that study were significantly elevated by even moderate impairment of renal function, an estimated glomerular filtration rate $<66 \mathrm{~mL} / \mathrm{min} / 1.73 \mathrm{~m}^{2}$ [17]. That level of renal function is average for vascular patients aged $>75$ years [18]. Patients with impaired renal function, including the elderly, should avoid egg yolk and red meat and limit meat intake. Those issues were recently reviewed [19].

Patients at risk of stroke should be encouraged to follow a Mediterranean diet, avoiding egg yolk and red meat and limiting meat intake. They should be provided with resources to help them succeed in that effort. The diet recommended to patients at the Stroke Prevention \& Atherosclerosis Research Center in London, Canada, is shown in Table 1. The recipe booklet provided to patients to help them with this approach can be downloaded from http://www.robarts.ca/SPARC/.

\section{B Vitamins to Lower Homocysteine}

Despite widespread belief to the contrary, it is now evident that using B vitamins to lower homocysteine reduces the risk of stroke. The benefit of B vitamins was obscured in early studies by harm from cyanocobalamin among participants with impaired renal function. This was evident in a meta-analysis stratified by renal function and dose of cyanocobalamin [20]. In a study of patients 
Table 1. Diet recommended for stroke prevention

High intake of whole grains, fruits, vegetables, nuts, lentils, beans, olive oil/canola oil

Limit intake of animal flesh to a serving the size of the palm every other day (or half that daily), or less, mainly fish and chicken, seldom red meat

No egg yolks: use egg white-based substitutes instead to make tasty omelets, frittatas, and egg salad sandwiches

The recipe booklet provided to patient attending the Stroke Prevention \& Atherosclerosis Research Center in London, Canada, can be downloaded from http://www.robarts.ca/SPARC/.

with diabetic nephropathy, B vitamins including $1,000 \mu \mathrm{g}$ daily of cyanocobalamin accelerated the decline of renal function and nearly doubled the risk of a composite of myocardial infarction, stroke, revascularization, and allcause mortality [21]. In contrast, stroke was reduced by $43 \%$ in the French Su.Fol.OM3 study, with the best renal function and the lowest dose of cyanocobalamin among trials that included cyanocobalamin (only $20 \mu \mathrm{g}$ daily vs. $400-1,000 \mu \mathrm{g}$ daily in the earlier studies). In the China Stroke Primary Prevention Trial, folic acid significantly reduced stroke in patients with hypertension; the reduction was greater among those with higher risk; ischemic stroke was reduced by $36 \%$ over 5 years among participants with LDL-C $>2 \mathrm{mmol} / \mathrm{L}$ [22]. Folic acid was beneficial among participants with impaired renal function [23]. The history of this complex issue was reviewed in 2019 [24]. Two more recent meta-analyses have confirmed that folic acid and $\mathrm{B}$ vitamin combinations reduce the risk of stroke $[25,26]$. Metabolic B12 deficiency with hyperhomocysteinemia is very common and easily treated [27]; the ongoing neglect of this opportunity to reduce the risk of stroke should not be permitted to persist.

\section{Smoking Cessation}

Smoking increases the risk of stroke 6-fold, and even passive smoking nearly doubles the risk of stroke [28]. All patients at risk of stroke should be strongly and repeatedly adviced to quit smoking, with counseling, adviced to use nicotine replacement therapy, and prescribed medications such as varenicline and bupropion. Patients should be advised that they must quit smoking and stop thinking of smoking cessation as something optional. The "parable of the cold lake," an approach borrowed from a Lancet article on diet, can be helpful: "If you are walking along the shore of a cold lake and your grand- child falls in, it doesn't take willpower to go into the lake; it simply must be done." A coordinated approach such as the Ottawa Model [29] is more successful than half-hearted approaches. In the Insulin Resistance Intervention after Stroke (IRIS) trial, participants who quit smoking had a $34 \%$ reduction in the 5-year risk of stroke, MI, or death compared to those who continued to smoke [30].

\section{Lipid Lowering}

It is now clear that lipid lowering is an important aspect of stroke prevention. Unfortunately, it is all too often not implemented or implemented only in a half-hearted way. A little bit of statin is not enough. Too often, highdose statins are avoided because of misplaced concern about adverse effects or omitted in the elderly because early trials did not include patients above the age of 80 . The only true causal adverse effects of statins are myopathy and a slight increase in the risk of diabetes. Statins do not cause cognitive impairment, renal impairment, cataracts, hepatotoxicity, intracerebral hemorrhage, or other adverse effects commonly attributed to them [24, 31]. Lipid lowering should be intensive, should include as high a dose of statin as tolerated, and should probably routinely include addition of ezetimibe. In some patients, therapies based on blocking PCSK9 should be considered, though cost is a limitation.

\section{Intensive Lipid Lowering}

The benefit of statins was underestimated in the Stroke Prevention by Aggressive Reduction in Cholesterol Level (SPARCL) trial, in part because many patients did not have large-artery disease and because many patients randomized to statin stopped it, and $25 \%$ of those randomized to placebo crossed over to statin. Among patients in SPARCL who had a $50 \%$ reduction of LDL-C (meaning they actually took the statin), there was a 33\% reduction of stroke, a $37 \%$ reduction of MI, and no increase in intracerebral hemorrhage [32]. Amarenco et al. [32] recently reported that among patients with a prior TIA or stroke, treating to a target LDL-C $<1.8$ versus $2.3-2.8 \mathrm{mmol} / \mathrm{L}$ reduced ischemic stroke by $33 \%$. In the SPARCL trial, lower LDL-C at 3 months was associated with a reduction of recurrent events; total events were prevented by atorvastatin twice as much as first events [33].

\section{Lipid Lowering in the Elderly and Ezetimibe}

Historical therapeutic nihilism regarding lipid lowering in old patients has now been debunked. It is now clear 
that older patients benefit from lipid lowering even more than younger patients because they have a higher risk and therefore a greater absolute risk reduction, resulting in lower NNT to prevent stroke [34].

In a trial of ezetimibe added to simvastatin, the NNT was only 11 for patients above age 75, versus 115 below age 75 . In a Japanese trial of ezetimibe versus placebo added to diet, in patients with a mean age of 80 years at baseline and followed up for 4 years, there was a $34 \%$ reduction of the composite outcome of sudden cardiac death, myocardial infarction, coronary revascularization, or stroke [35].

It is an important error to equate lipid lowering with statins alone; ezetimibe should be used routinely for stroke prevention. Whereas statins block the synthesis of cholesterol, ezetimibe blocks the absorption of cholesterol and other sterols. By blocking 2 mechanisms, the combination of ezetimibe with statin is synergistic; $10 \mathrm{mg}$ of ezetimibe with $40 \mathrm{mg}$ of atorvastatin lowers LDL by almost as much as $80 \mathrm{mg}$ of atorvastatin. By combining ezetimibe with statin, lower doses of statin can be used, thereby minimizing adverse effects. In a trial in which ezetimibe or placebo was added to simvastatin, ezetimibe reduced stroke by $21 \%$ overall, but as discussed above, the effect was greater in older patients [36]. The European guideline on dyslipidemia now recommends addition of ezetimibe in patients who do not achieve lipid targets with statin alone [37].

\section{Hypertension}

Hypertension is probably the most important risk factor for stroke, and it is poorly treated. Controlling blood pressure well reduces the risk of stroke by half and virtually eliminates intracranial hemorrhage. After the Department of Family Medicine at Western University in London, ON, Canada, implemented in 1978 a large program to improve blood pressure control in the community [38], the detection and treatment of hypertension improved markedly. In that era, the "rule of halves" prevailed in North America: only half of hypertension was detected, of that only half (25\%) was being treated, and of that, only half $(12.5 \%)$ of the patients were controlled. By 1983, in Middlesex County, which surrounds the city, $94 \%$ of hypertension was detected, $92 \%$ of hypertensive patients were being treated, and $72 \%$ had their blood pressure controlled [39]. The result of that was a $50 \%$ reduction of stroke [40]. In part, that success was related to the establishment in 1977 of a hypertension clinic that based therapy for resistant hypertension on measurement of stimulated renin [41], as discussed below. The stroke subtypes that were preferentially reduced were those due to hypertensive small-vessel disease: lacunar infarctions and intracerebral hemorrhages [40]. In the North American Carotid Endarterectomy Trial, strenuous efforts were made to achieve benchmark blood pressures. A stiff letter was sent to the site investigator every time a patient attended clinic with a blood pressure above target if antihypertensive therapy was not intensified. The result of this was that at a time when $\sim 20 \%$ of strokes were due to intracranial bleeding, intracranial bleeds in the medical arm of the North American Carotid Endarterectomy Trial were reduced to $0.5 \%$. That total included subarachnoid and lobar hemorrhages; that is, hypertensive intracerebral hemorrhages were virtually eliminated.

\section{Resistant Hypertension}

A population-based study in Sweden reported that among persons being treated for hypertension, $90 \%$ of strokes occurred in patients with uncontrolled hypertension [42]. It was estimated that strokes could have been reduced by $45 \%$ by controlling blood pressure. The causes of resistant hypertension include noncompliance, consumption of substances that aggravate hypertension (salt, licorice, nonsteroidal anti-inflammatory agents other than sulindac, decongestants, and excess alcohol), therapeutic inertia (failure to intensify therapy when blood pressure is not controlled), and diagnostic inertia (failure to investigate the cause of the hypertension so that appropriate therapy can be identified). Approximately half of non-compliant patients will admit it if questioned in a nonjudgemental way [43], and pharmacy records and sometimes blood levels of drugs can be checked to detect noncompliance [44]. Salt intake should be reduced to 2-3 g/day [45], sulindac should replace other NSAIDs [46], decongestants can be replaced, and alcohol intake should be moderate. Perhaps the most important missed opportunity is diagnostic inertia.

\section{Physiologically Individualized Therapy for Resistant Hypertension}

Blood pressure control can be markedly improved by physiologically individualized therapy based on renin/aldosterone phenotyping (PhysRx). There are 3 key phenotypes: low renin/high aldosterone (inappropriate aldosterone secretion), low renin/low aldosterone (a Liddle phenotype, due to overactivity of the renal epithelial sodium channel, $\mathrm{ENaC}$ ), and high renin/high aldosterone (secondary aldosteronism, due to excess renin production re- 
Table 2. Physiologically individualized therapy for control of resistant hypertension ${ }^{\mathrm{a}}$

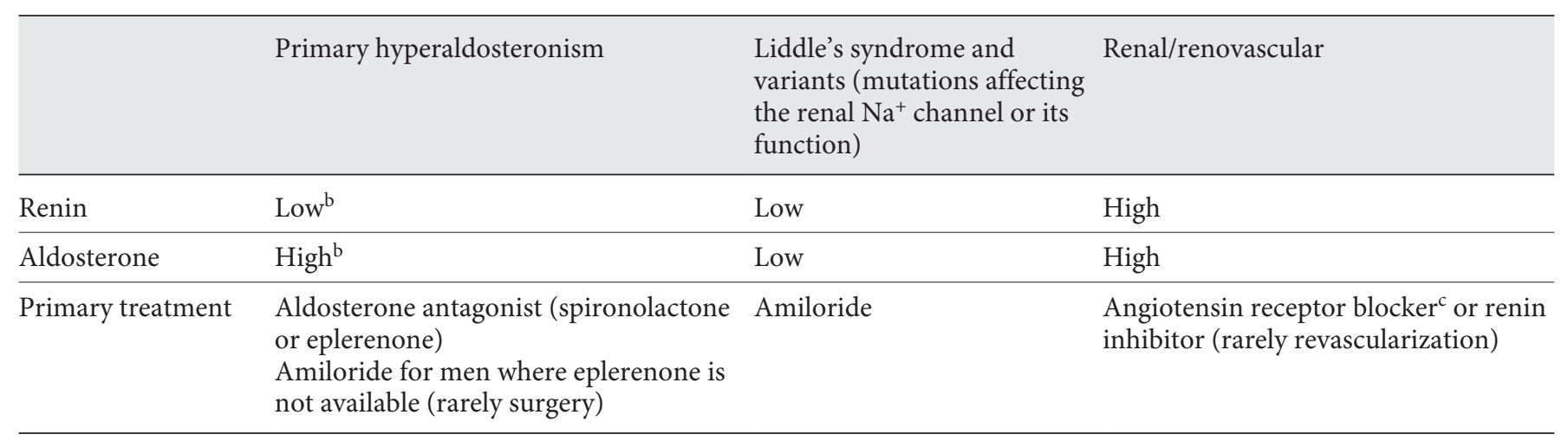

Reproduced by permission of Oxford University Press from Akintunde A, Nondi J, Gogo K, Jones ESW, Rayner BL, Hackam DG, and Spence JD. Physiological phenotyping for personalized therapy of uncontrolled hypertension in Africa. Am J Hypertens. 2017; 30(9):923-30. ${ }^{\text {a }}$ It should be stressed that this approach is suitable for tailoring medical therapy in resistant hypertensives; further investigation would be required to justify adrenalectomy or renal revascularization. ${ }^{b}$ Levels of plasma, renin, and aldosterone must be interpreted in the light of the medication the patient is taking at the time of sampling. In a patient taking an angiotensin receptor blocker (which would elevate renin and lower aldosterone), a plasma renin that is in the low normal range for that laboratory, with a plasma aldosterone in a high normal range, probably represents primary hyperaldosteronism, for the purposes of adjusting medical therapy. ${ }^{c}$ Angiotensin receptor antagonists are less effective because of the aldosterone escape via non-ACE pathways, such as chymase and cathepsin; renin inhibitors are seldom used.

sulting from renal disease such as cysts, renal artery stenosis, obstruction, or hypertensive nephrosclerosis). Some patients whose hypertension begins with a low-renin phenotype may develop secondary hyperaldosteronism as a result of hypertensive nephrosclerosis, renal artery stenosis, or polycystic kidneys, but most patients with resistant hypertension can have their blood pressure control markedly improved by PhysRx.

Suppressed renin due to salt and water retention is more common in black patients. There are 2 streams of low-renin hypertension: inappropriate aldosterone secretion (low renin/high aldosterone), for which aldosterone antagonists are the best treatment, and the Liddle phenotype (low renin/low aldosterone), for which amiloride is the best therapy. There are variants of at least 6 genes that cause inappropriate aldosterone secretion (CYP11B2, KCNJ5, ATP1A1, ATP2B3, CACNA1D, and $A R M C 5)$ and variants of at least 6 genes that cause the Liddle phenotype (SCNN1B, true Liddle syndrome, as well as GRK, NEDD4L, CYP4A11, NPPA, and UMOD) [47]; probably others are yet to be discovered. Variants of those genes were very common in patients with uncontrolled hypertension in the African study described below [48].

The algorithm for selection of therapy based on PhysRx is shown in Table 2. In a study in Africa [49], patients with uncontrolled hypertension were allocated to usual care versus PhysRx. The strategy was not successful at the site in Kenya, where amiloride was not available, patients attended the clinic less often, and the cost of medication was prohibitive. At the Nigerian site, where care more closely resembled that in developed nations, and patients were randomized to the 2 treatment strategies, "systolic control was obtained in $15 \%$ of usual care versus $85 \%$ of PhysRx $(p=0.0001)$, diastolic control in 45 versus $75 \%(p=0.11)$, and control of both systolic and diastolic pressure in 15 versus $75 \%(p<0.0001)$ even though the renal function was worse at that site." This strategy has the potential to markedly improve control of hypertension and lessen the stroke disparity among African Americans; it should be used routinely in resistant hypertension [50]. Our Neurology colleagues may demur, saying that they leave control of hypertension to the internist or the family physician. The unfortunate consequence of that approach is that it does not happen. A recent study documented that in the Veteran's Administration hypertension clinics, diagnostic inertia was highly prevalent: only $1.6 \%$ of the patients with resistant hypertension were tested for primary aldosteronism [51], even though it accounts for $22 \%$ of resistant hypertension [52]. The most neglected cause of hypertension is the Liddle phenotype. Guidelines do not mention Liddle syndrome, and amiloride, the specific therapy for the Liddle phenotype, is mentioned only as an alternative to spironolactone for primary aldosteronism [53]. 
Risk of Diastolic Pressure $<60 \mathrm{~mm} \mathrm{Hg}$ with Pulse

Pressure $>60 \mathrm{~mm} \mathrm{Hg}$

Another neglected topic in hypertension is the relatively recent recognition that low systolic blood pressure targets $<120 \mathrm{~mm} \mathrm{Hg}$ which is not safe in a subgroup of elderly frail patients with stiff arteries. McEvoy et al. [54] reported that patients with diastolic pressure $<60 \mathrm{~mm} \mathrm{Hg}$ and a pulse pressure $>60 \mathrm{~mm} \mathrm{Hg}(\mathrm{DBP}<60 / \mathrm{PP}>60)$ had a doubling of subclinical myocardial ischemia; Park and Ovbiagele [55] reported that such patients had a 5.85-fold increase in the risk of stroke. Reasons for this phenomenon were recently summarized [56]: (1) wide pulse pressures are due to stiff arteries; (2) patients with stiff arteries are more likely to have a large cuff artifact, with the cuff diastolic pressure measuring substantially higher than the true intra-arterial pressure; (3) virtually all of myocardial perfusion and more than half of cerebral perfusion occurs during the diastole; (4) there is a large pressure gradient in the brain: "When the pressure in the brachial artery is $117 / 75 \mathrm{~mm} \mathrm{Hg}$, it is $113 / 73 \mathrm{~mm} \mathrm{Hg}$ in the lenticulostriate artery but only $59 / 39 \mathrm{~mm} \mathrm{Hg}$ in small branches in the posterior parietal subcortex" [57].

Patients with DPB $<60 / \mathrm{PP}>60$ may have diastolic pressures that are below the critical perfusion pressure if their systolic pressure is lowered too far. Elderly patients with hypotensive symptoms at blood pressures that seem too high to explain them should be suspected of having a large cuff artifact ("pseudohypertension" [58]); blood pressure targets should be reconsidered, and if feasible, intra-arterial pressure should be measured to clarify the situation.

\section{Diabetes}

Diabetes is an important risk factor for stroke. In the Honolulu Heart Study, diabetes increased the 22-year risk of stroke 3.47-fold [59]. A report from the Nurses' Health Study [60] indicated that type II diabetes preferentially increased lacunar and large-artery stroke, whereas type I diabetes was also associated with hemorrhagic stroke (it seems likely that hypertension due to diabetic nephrosclerosis explains that finding). Great advances have been made in the treatment of diabetes with new drug classes, such as gliptins, but treatment of insulin resistance with thiazolidinediones, particularly pioglitazone, has been a missed opportunity. Thiazolidinediones have been largely avoided, for reasons that do not stand up to scrutiny. Evidence for an increased risk of bladder cancer is weak, and if there is a risk, it is very low:
$0.0066 \%$ per year, based on a meta-analysis that reported marked heterogeneity among studies [61]. Pantoni reviewed reasons for the mistaken reluctance to use them [62], and others have called for an end to this nihilism.

\section{Pioglitazone}

Insulin resistance is very common, particularly in obese patients and South Asians. It is associated with high triglycerides, low high-density lipoprotein cholesterol, coagulation, inflammation, and vascular reactivity. Weight loss and exercise improve sensitivity to insulin, and the most potent drug therapy for insulin resistance is with thiazolidinediones. Pioglitazone is a potent agonist of peroxisome proliferator-activated receptor $-\gamma$ and a weak agonist of peroxisome proliferator-activated receptor- $\alpha$. It has common adverse effects in the highest dose of $45 \mathrm{mg}$ daily: in a study in prediabetics, fluid retention occurred in $29 \%$ of the patients taking it versus $22 \%$ of patients on placebo; and weight gain affected $29 \%$ of patients taking it versus $12 \%$ of the patients on placebo. For that reason, intention-to-treat analyses (ITT) are not appropriate for therapeutic decisions in individual patients [63].

An ITT analysis of the IRIS trial reported that in patients with a prior stroke and with insulin resistance defined by the homeostasis model, pioglitazone reduced new-onset diabetes by $52 \%$ and reduced nonfatal stroke and myocardial infarction (stroke/MI) by $24 \%$ [64]. An ITT analysiss of pioglitazone for secondary stroke prevention in the PROspective pioglitAzone Clinical Trial In macroVascular Events (PROactive) trial reported a 47\% reduction of stroke [65], and a meta-analysis conducted prior to the study described below reported a $32 \%$ reduction of recurrent stroke with pioglitazone [66].

In a subgroup analysis of IRIS participants with prediabetes [67], defined by hemoglobin A1c level of 5.7$6.4 \%$, the primary analysis was an on-treatment analysis (defined by taking $\geq 80 \%$ of the protocol dose of $45 \mathrm{mg}$ ). That analysis revealed an $82 \%$ reduction of new-onset diabetes and a $43 \%$ reduction of stroke/MI over 5 years. The NNT to prevent 1 case of diabetes was 12 , the number to prevent 1 stroke/MI was 25, and the NNT to cause 1 serious fracture was 125 [67]. The results are shown in Figure 1. The ITT analysis gave similar results, but as expected, risk reduction and adverse effects were less significant. Low-dose pioglitazone minimizes adverse effects while retaining much of the benefit $[68,69]$. Pioglitazone should be much more widely used for stroke prevention. 
Stroke or myocardial infarction

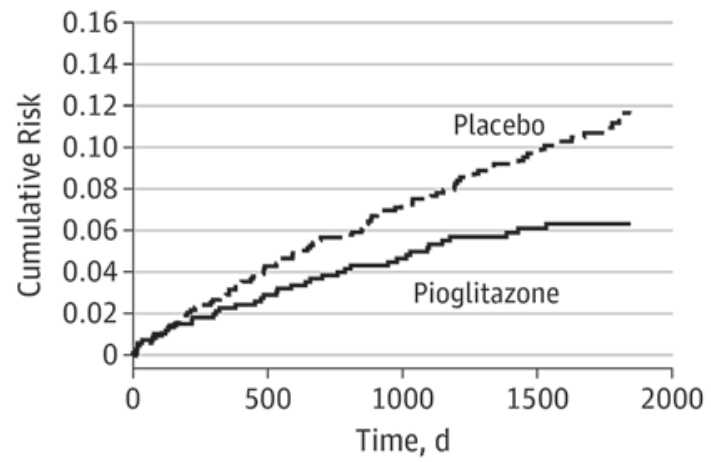

No. at risk

$\begin{array}{lllll}\text { Pioglitazone } & 644 & 613 & 553 & 414 \\ \text { Placebo } & 810 & 752 & 660 & 470\end{array}$

Acute coronary syndrome

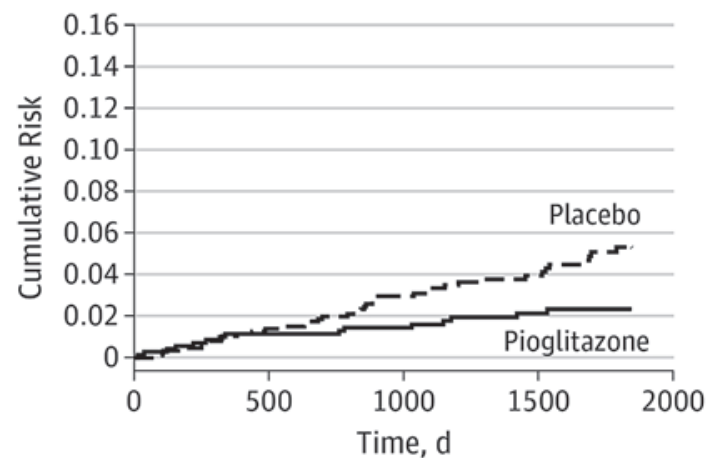

No. at risk

$\begin{array}{lllll}\text { Pioglitazone } & 644 & 623 & 569 & 430 \\ \text { Placebo } & 810 & 772 & 682 & 492\end{array}$

c

Diabetes

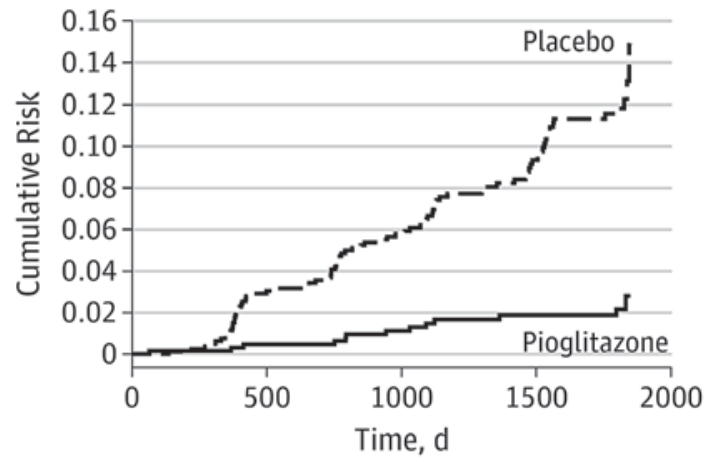

No. at risk

$\begin{array}{lllll}\text { Pioglitazone } & 644 & 627 & 569 & 428\end{array}$

e
Stroke

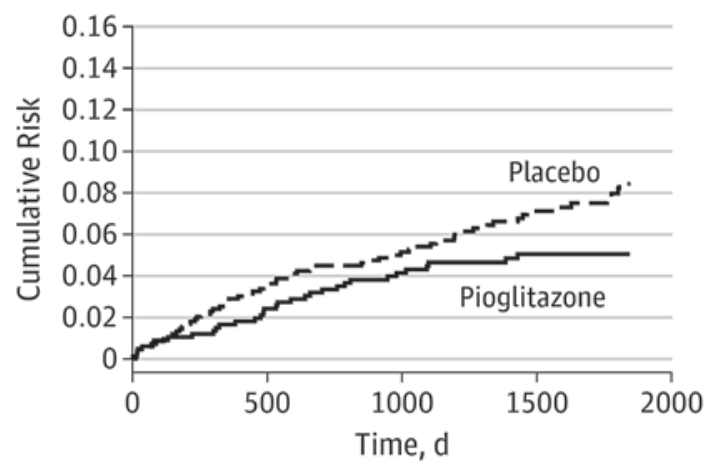

No. at risk

$\begin{array}{lllll}\text { Pioglitazone } & 644 & 615 & 555 & 415 \\ \text { Placebo } & 810 & 757 & 673 & 484\end{array}$

Stroke/MI/HHF

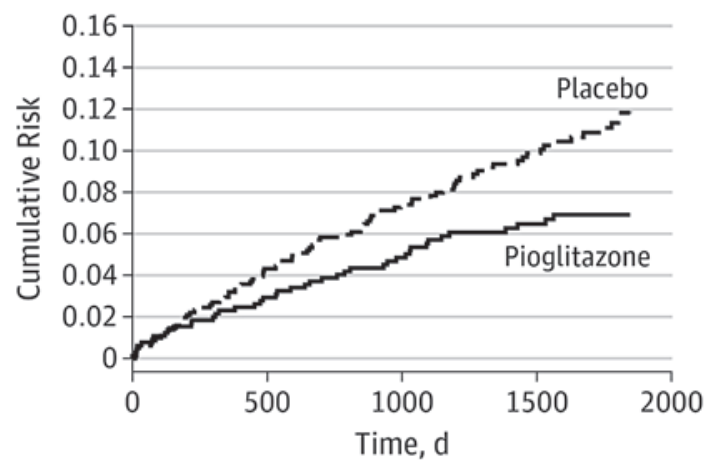

No. at risk

$\begin{array}{lllll}\text { Pioglitazone } & 644 & 613 & 553 & 413\end{array}$

d 


\section{Antiplatelet Therapy}

Antiplatelet therapy has been standard for secondary stroke prevention in patients with large-artery disease since the Canadian aspirin/sulfinpyrazone study in 1980 [70]. However, aspirin reduces recurrent stroke by only $\sim 25 \%$, and other antiplatelet agents, or dual antiplatelet therapy, are not great deal breakers. Two important issues are neglected: the effect of variants of CYP2C19 that reduce efficacy of clopidogrel, and the effect of enteric coating on aspirin resistance. One curious issue in antiplatelet therapy is the nonuse of cilastozol outside of Asia; probably this deserves more attention.

\section{CYP2C19 Variants}

Clopidogrel is a prodrug that must be oxidized by CYP2C19 to be activated. Variants of that gene that result in clopidogrel being ineffective [71] are common, being present in $\sim 30 \%$ of Europeans and $>50 \%$ of Chinese [71]. Although such findings have led to calls for pharmacogenetic testing, it would be simpler to use ticagrelor or prasugrel instead. A recent study indicated that prasugrel was superior to ticagrelor in acute coronary syndrome [72].

\section{Enteric-Coated Aspirin}

Aspirin resistance is a complicated topic of dubious significance. However, it transpires that enteric coating accounts for "pseudoresistance" to aspirin among a high proportion of patients thought to be aspirin resistant [73, $74]$. We should probably be using uncoated aspirin, instead of coated aspirin. The risk of gastrointestinal bleeding could be minimized by detecting and treating helicobacter pylori, or perhaps by proton pump inhibitors in selected patients with gastritis from aspirin.

One of the most common errors in stroke prevention is a knee-jerk reaction of switching to clopidogrel in patients who have TIA or stroke while taking aspirin. If aspirin has failed and antiplatelet therapy is indicated, it would probably be better to add a second antiplatelet agent. More importantly, if aspirin has failed, the need for anticoagulation should be suspected [75].

Fig. 1. Secondary stroke prevention with pioglitazone in patients with prediabetes. a Stroke or myocardial infarction (HR, $0.57 ; 95 \%$ CI, 0.39-0.84; $p=0.004$ ). b Stroke (HR, 0.64; 95\% CI, 0.42-0.99; $p=0.04)$. c Acute coronary syndrome (HR, 0.47; 95\% CI, 0.26$0.85 ; p=0.01)$. d Stroke/MI/HHR (HR, 0.61; 95\% CI, 0.42-0.88; $p=0.008$ ). e New-onset diabetes (HR, 0.18; 95\% CI, 0.10-0.33; $p<$ 0.001). (Permission requested of the American Heart Association

\section{Anticoagulation}

\section{White Thrombus versus Red Thrombus}

Antiplatelet agents prevent "white thrombus," platelet aggregates that form in the setting of fast flow, usually on atherosclerotic plaques, and embolize distally (Fig. 2). That is what antiplatelet agents prevent; antiplatelet agents are not anticoagulants. Red thrombus, a mesh of fibrin polymer with entrapped red cells, forms in the setting of stasis [76, 77] (e.g., a deep vein thrombosis or an atrial appendage). Anticoagulants are needed to prevent red thrombus.

\section{Anticoagulation for ESUS}

Although in the past, when warfarin was the mainstay of anticoagulation, the paradigm was essentially "we

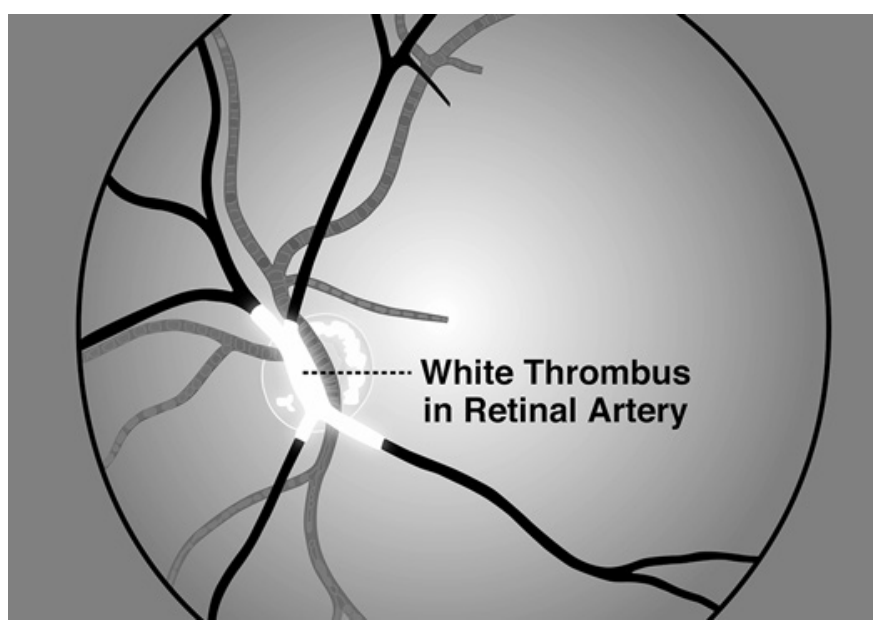

Fig. 2. White thrombus. White thrombus is shown in the retinal artery of a patient with amaurosis fugax. This phenomenon was described by C. Miller Fisher in a case presented at Grand Rounds at the Massachusetts General Hospital. JDS has seen this twice by ophthalmoscopy when he happened to be in the room with a patient who suddenly lost vision in one eye. The white thrombus oozes slowly through the retinal arteries, with vision returning as blood flow is restored; the vision may be restored in quadrants or a hemifield as branches of the retinal artery clear serially (reproduced by permission of Vanderbilt University Press from: Spence J.D; How to prevent your stroke; Vanderbilt University Press 2006).

to reproduce from Spence JD, Viscoli CM, Inzucchi SE, DearbornTomazos J, Ford GA, Gorman M, et al. Pioglitazone therapy in patients with stroke and prediabetes: a post hoc analysis of the IRIS randomized clinical trial. JAMA Neurol. 2019; 76(5):526-35). HR, hazard ratio; CI, confidence; MI, myocardial infarction; HHR, hospitalization for heart failure; IRIS, insulin resistance intervention after stroke. 
Table 3. Properties of DOACs

\begin{tabular}{lllll}
\hline Property & Rivaroxaban & Dabigatran & Apixaban \\
\hline Clotting factor target & Factor Xa & Factor IIa & Factor Xa & Fo \\
Requires metabolism for activation & No & Yes & No & Twice daily \\
Dosing frequency & Daily & Twice daily & $50 \%$ & Daily \\
Bioavailability & $80-100 \%$ & $6.5 \%$ & $8-15$ & $62 \%$ \\
Half-life, $h$ & $5-13$ & $12-14$ & $27 \%$ & $10-14$ \\
Renal clearance & $\sim 33 \%$ & $85 \%$ & $3-4$ & $1-2 \%$ \\
Time to peak blood level, h & $2-4$ & $1-2$ & Strong inhibitors of & P-gp inhibitors \\
Drug interactions & Strong inhibitors of & P-gp inhibitors & CYP3A4 and P-gp \\
\hline
\end{tabular}

Reproduced by permission of Wolters Kluver Health from Spence JD, Azarpazhooh MR, Larsson SC, Bogiatzi C, and Hankey GJ. Stroke prevention in older adults: recent advances. Stroke. 2020; 51(12):3770-7. DOACs, direct-acting oral anticoagulants; CYP3A4, intestinal cytochrome; P-gp, P-glycoprotein.

would never anticoagulate a patient unless we identify a definite cardioembolic source, such as atrial fibrillation." However, with the advent of direct-acting oral anticoagulants (DOACs), everything has changed. DOACs are not significantly more likely than warfarin to cause severe bleeding $[78,79]$, so in a patient in whom a cardioembolic source is strongly suspected, it is more prudent to prescribe DOACs than to persist with antiplatelet agents [80]. Although some might think that dual antiplatelet therapy would be a better alternative to anticoagulation for atrial fibrillation, it is not: adding clopidogrel to aspirin in patients with atrial fibrillation reduced stroke by only $0.67 \%$ [81]. Studies of antiplatelet agents versus DOACs have for the most part not shown benefit of DOACs in patients with ESUS; neither rivaroxaban [82] nor dabigatran [83] was significantly better than aspirin in unselected patients with ESUS. However, it is very likely that this result was due to misclassification of large-artery atherosclerosis as ESUS. The studies defined large-artery disease as a $50 \%$ stenosis, which misses $79 \%$ of cases due to large-artery disease defined by a high plaque burden, as in the Subtypes of Ischemic Stroke classification (SPARKLE) [84] and Chinese Ischemic Stroke Subtype (CISS) classifications [85]. In contrast, in the NAVIGATE-ESUS substudy, in participants with patent foramen ovale [86], a meta-analysis reports a significant benefit of anticoagulation versus aspirin; the odds ratio favored anticoagulation: 0.48 (95\% CI 0.24-0.96).

Too often, anticoagulants are avoided in old patients, perhaps because of fear of falls. It has been calculated that it would take 295 falls to equal the risk of not anticoagulating a patient with atrial fibrillation [87]. The elderly benefit from anticoagulation for atrial fibrillation even more than younger patients $[88,89]$; more should be anticoagulated, but it should be with DOACs rather than warfarin.

\section{Direct-Acting Oral Anticoagulants}

There are important differences among DOACs that should be considered (Table 3 ). It has become clear that rivaroxaban (and probably edoxaban) should not be used as a once-daily drug; it is not longer acting than other DOACs. The problem is illustrated in Figure 3. Indeed, recent studies of rivaroxaban plus aspirin for peripheral vascular disease have used twice-daily dosing of rivaroxaban. Apixaban is the least renally eliminated of the DOACs; this is important in the elderly because renal function declines with age. Those 2 factors may explain why a large population-based study reported that apixaban was safer and more effective than rivaroxaban [90].

Dabigatran is problematic for several reasons: it causes heartburn in $\sim 20 \%$ of the patients, it is the most renally eliminated of the DOACs and by far the least bioavailable (only 6\%). The latter issue means that it is subject to very large changes in blood levels with changes in absorption or with drug interactions. There are reasons to consider that blood levels of dabigatran should be monitored, thus eliminating one of the main benefits of DOACs over warfarin [91].

\section{Intervention for Carotid Stenosis}

Carotid endarterectomy (CEA) or stenting are more beneficial for symptomatic than for asymptomatic carotid stenosis (ACS). With increasingly intensive medical therapy, the risk of stroke or death in patients with ACS is now 
Fig. 3. Once-daily versus twice-daily dosing: difference between intake and predicted biological impact in general. Different patterns of nonadherence lead to different exposition to "risk" between once- and twice-daily drugs. These graphs illustrate the theoretical pharmacokinetic profiles of QD and BID for a drug with a half-life of about $12 \mathrm{~h}$ and a $T_{\max }$ of $3 \mathrm{~h}$. a The peak-totrough ratio is much smaller for the BID than the QD dosing. b The concentration after a single missed BID dose (red dot) is similar to the expected trough concentration of QD dosing, suggesting that missing a single dose of a twice-daily dosing regimen should not be therapeutically critical. c The pharmacological equivalent of missing a single dose in a once-daily regimen (blue dot) is missing 3 consecutive doses (red dots) of a twice-daily dosing regimen. d Taking an extra dose results in a much higher peak for the QD than for the BID dosing regimen (Reproduced by permission of Oxford University Press from Heidbuchel $\mathrm{H}$ and Vrijens B. Nonvitamin $\mathrm{K}$ antagonist oral anticoagulants: considerations on once- vs. twice-daily regimens and their potential impact on medication adherence. EP Europace. 2015; 17:1317131824.). QD, dose $\mathrm{X}$ administered once daily; BID, dose $\mathrm{X} / 2$ administered twice daily.

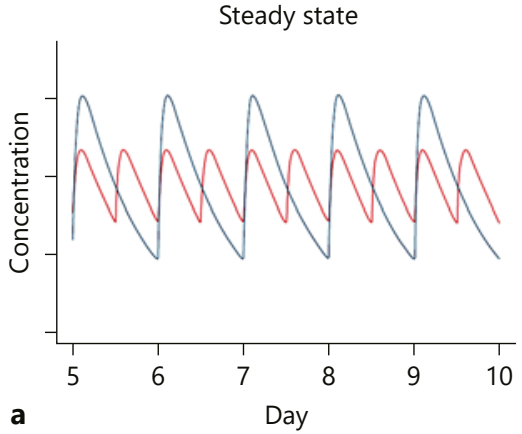

1 missed QD dose equals 3 missed BID doses

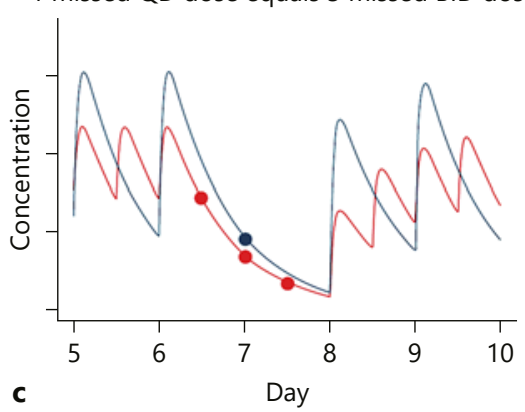

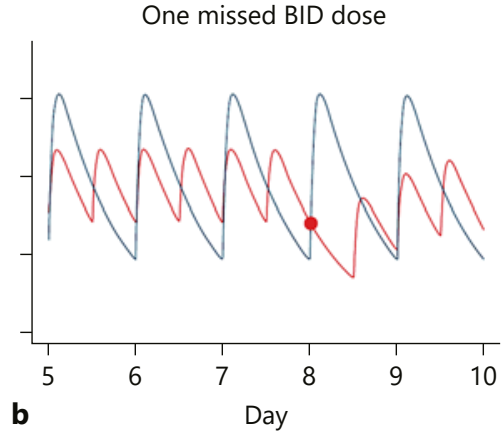

One extra dose

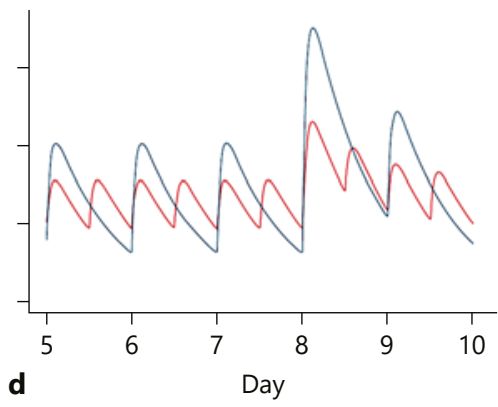

below the risk of either CEA or carotid artery stenting (CAS); the annual risk of stroke is $\sim 0.5 \%$ with intensive medical therapy $[92,93]$, whereas the 30 -day risk of stroke or death even in highly regulated clinical trials was 2.5$2.9 \%$ for CAS and $1.4-1.7 \%$ for CEA. In the real world, risks of intervention are higher. This means that CEA or CAS should not be performed routinely for ACS; only selected patients who can be identified as having a high enough risk to benefit should be subjected to these procedures. Rothwell et al. reported in 2021 that percent stenosis predicted higher risk in participants in the Oxford Vascular Study [94]. However, the study participants did not have true ACS; they were imaged because of TIA or stroke and found to have an asymptomatic carotid artery, so the reported risk may be an overestimate [95].

\section{Identifying which Patients with Asymptomatic Could Benefit from Intervention}

Ways to identify high-risk patients with ACS were reviewed in 2018 [96]. They include microemboli on tran- scranial Doppler, intraplaque hemorrhage on MRI, ulceration, echolucency (particularly juxtaluminal black plaque), and reduced cerebrovascular reserve. The 2017 European Society for Vascular Surgery carotid guidelines [97] endorsed these indications and some others.

\section{Effect of Age on Risk of Stenting versus}

\section{Endarterectomy}

There are risks to shoving a catheter into a stiff craggy carotid artery. Microemboli are commonly dislodged while crossing the aortic arch, deploying the protection device, and deploying the stent. Almekhlafi documented that a substantial number of such microemboli were large, termed "malignant" microemboli [98]. They reported that $80 \%$ of the patients had new diffusionweighted lesions which were seen in $80 \%$ of the patients after stenting, and the clinical condition of the patient declined in $6.7 \%$ of the patients after CAS. Older patients are more likely to have stiff, tortuous craggy arteries; it is probably for that reason that there is a much 


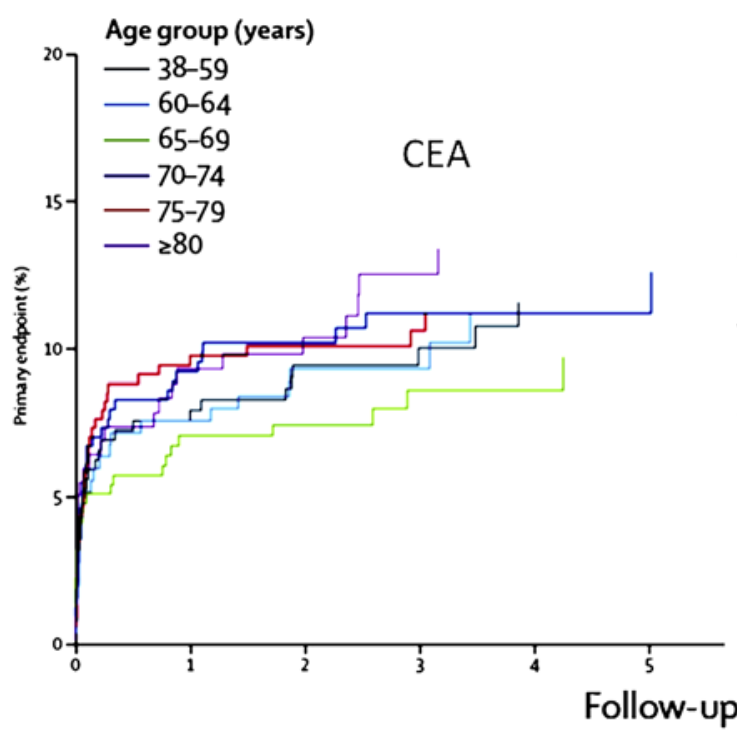

Fig. 4. Estimated event rates for patients assigned to CEA (a) and CAS (b) by age stratum. The age-groups are shown by the color key. Events plotted during the first 120 -day periprocedural period include stroke in either hemisphere plus deaths, whereas events during the postprocedural period include ipsilateral stroke only. Patients were censored at 6 years for the graphical presentation of

higher risk with CAS than with CEA above age 70 (Fig. 4). For most older patients, CEA would therefore be preferable to CAS. "Factors that would favor CAS could include younger age, specific anatomical features (such as a stenosis, i.e., in the very distal internal carotid artery), lack of tortuosity of the arteries leading to the stenosis, absence of or only minimal plaque calcification, presence of local tissue scarring due to previous surgery or radiation, and conditions conferring a high medical risk for surgery (such as congestive heart failure, myocardial ischemia, or severe pulmonary disease) [99].

\section{Conclusion}

There are a number of little-known/neglected aspects of stroke prevention that in our opinion, if better recognized and applied, could substantially reduce the risk of stroke. These include aspects of nutrition, lipid-lowering therapy, physiologically individualized therapy for hypertension, more rational use of antiplatelet agents and anticoagulants, and more judicious application of CEA and CAS. event rates. (Reproduced by permission of Elsevier from Howard G, Roubin GS, Jansen O, Hendrikse J, Halliday A, Fraedrich G, et al., Association between age and risk of stroke or death from carotid endarterectomy and carotid stenting: a meta-analysis of pooled patient data from 4 randomized trials. Lancet 2016;67:13051311). CAS, carotid artery stenting; CEA, carotid endarterectomy.

\section{Acknowledgement}

This paper is published in celebration of the 30th anniversary of the inception of Cerebrovascular Diseases 1991-2021.

\section{Funding Sources}

The authors did not receive any funding.

\section{Conflict of Interest Statement}

Dr. Azarpazhooh and Dr. Bogiatzi have no disclosures. Prof. Spence is a consultant to Amgen and Orphan Technologies and an unpaid officer of Vascularis Inc. He also received a lecture fee from BMS/Pfizer.

\section{Author Contributions}

J.D.S. wrote the first and final drafts; C.B. and M.R.A. contributed to revisions. 


\section{References}

1 Hackam DG, Spence JD. Combining multiple approaches for the secondary prevention of vascular events after stroke: a quantitative modeling study. Stroke. 2007;38(6): 1881-5.

2 Chiuve SE, Rexrode KM, Spiegelman D, Logroscino G, Manson JE, Rimm EB. Primary prevention of stroke by healthy lifestyle. Circulation. 2008;118(9):947-54.

3 Chiuve SE, McCullough ML, Sacks FM, Rimm EB. Healthy lifestyle factors in the primary prevention of coronary heart disease among men: benefits among users and nonusers of lipid-lowering and antihypertensive medications. Circulation. 2006;114(2):160-7.

4 Larsson SC, Akesson A, Wolk A. Healthy diet and lifestyle and risk of stroke in a prospective cohort of women. Neurology. 2014;83(19): 1699-704.

5 Akesson A, Larsson SC, Discacciati A, Wolk A. Low-risk diet and lifestyle habits in the primary prevention of myocardial infarction in men: a population-based prospective cohort study. J Am Coll Cardiol. 2014;64(13):1299306.

6 O'Keefe JH, Torres-Acosta N, O'Keefe EL, Saeed IM, Lavie CJ, Smith SE, et al. A pescomediterranean diet with intermittent fasting: JACC review topic of the week. J Am Coll Cardiol. 2020;76(12):1484-93.

7 Rees K, Hartley L, Flowers N, Clarke A, Hooper L, Thorogood M, et al. 'Mediterranean' dietary pattern for the primary prevention of cardiovascular disease. Cochrane $\mathrm{Da}$ tabase Syst Rev. 2019;3(8):CD009825.

8 Keys A. Mediterranean diet and public health: personal reflections. Am J Clin Nutr. 1995 61(6 Suppl 1):1321S-3S.

9 Willett WC, Sacks F, Trichopoulou A, Drescher G, Ferro-Luzzi A, Helsing E, et al. Mediterranean diet pyramid: a cultural model for healthy eating. Am J Clin Nutr. 1995;61(6 Suppl 1):1402S-6S.

10 Shai I, Schwarzfuchs D, Henkin Y, Shahar DR, Witkow S, Greenberg I, et al. Weight loss with a low-carbohydrate, Mediterranean, or low-fat diet. N Engl J Med. 2008;359(20): 2169-2.

11 Renaud S, de Lorgeril M, Delaye J, Guidollet J, Jacquard F, Mamelle N, et al. Cretan Mediterranean diet for prevention of coronary heart disease. Am J Clin Nutr. 1995;61(6 Suppl l):1360S-7S.

12 Randomized trial of cholesterol lowering in 4,444 patients with coronary heart disease: the Scandinavian Simvastatin Survival Study (4S). Lancet. 1994;344:1383-9.

13 Estruch R, Ros E, Salas-Salvadó J, Covas MI, Corella D, Arós F, et al. Primary prevention of cardiovascular disease with a Mediterranean diet supplemented with extra-virgin olive oil or nuts. N Engl J Med. 2018;378(25):e34.

14 Zhong VW, Van Horn L, Cornelis MC, Wilkins JT, Ning H, Carnethon MR, et al. Associations of dietary cholesterol or egg con- sumption with incident cardiovascular disease and mortality. JAMA. 2019;321(11):1081-95.

15 Tang WH, Wang Z, Levison BS, Koeth RA, Britt EB, Fu X, et al. Intestinal microbial metabolism of phosphatidylcholine and cardiovascular risk. N Engl J Med. 2013;368(17): 1575-84.

16 Bogiatzi C, Gloor G, Allen-Vercoe E, Reid G, Wong RG, Urquhart BL, et al. Metabolic products of the intestinal microbiome and extremes of atherosclerosis. Atherosclerosis. 2018;273:91-7.

17 Pignanelli M, Bogiatzi C, Gloor G, Allen-Vercoe E, Reid G, Urquhart BL, et al. Moderate renal impairment and toxic metabolites produced by the intestinal microbiome: dietary implications. J Ren Nutr. 2019;29(1):55-64.

18 Spence JD, Urquhart BL, Bang H. Effect of renal impairment on atherosclerosis: only partially mediated by homocysteine. Nephrol Dial Transplant. 2016;31(6):937-44.

19 Spence JD, Srichaikul K, Jenkins DJA. Cardiovascular harm from egg yolk and meat: more than just cholesterol and saturated fat. JAHA. 2021 Mar 15:e017066.

20 Spence JD, Yi Q, Hankey GJ. B vitamins in stroke prevention: time to reconsider. Lancet Neurol. 2017;16(9):750-60.

21 House AA, Eliasziw M, Cattran DC, Churchill DN, Oliver MJ, Fine A, et al. Effect of B-vitamin therapy on progression of diabetic nephropathy: a randomized controlled trial. JAMA. 2010;303(16):1603-9.

22 Qin X, Li J, Spence JD, Zhang Y, Li Y, Wang $\mathrm{X}$, et al. Folic acid therapy reduces the first stroke risk associated with hypercholesterolemia among hypertensive patients. Stroke. 2016;47(11):2805-12.

23 Xu X, Qin X, Li Y, Sun D, Wang J, Liang M, et al. Efficacy of folic acid therapy on the progression of chronic kidney disease: the renal substudy of the China Stroke Primary Prevention Trial. JAMA Intern Med. 2016;176(10): 1443-50.

24 Spence JD. The need for clinical judgement in the application of evidence-based medicine. BMJ Evid Based Med. 2020 Oct;25(5):172-7.

25 Jenkins DJA, Spence JD, Giovannucci EL, Kim YI, Josse R, Vieth R, et al. Supplemental vitamins and minerals for CVD prevention and treatment. J Am Coll Cardiol. 2018; 71(22):2570-84.

26 Jenkins DJA, Spence JD, Giovannucci EL, Kim YI, Josse RG, Vieth R, et al. Supplemental vitamins and minerals for cardiovascular disease prevention and treatment: JACC focus seminar. J Am Coll Cardiol. 2021;77(4):42336.

27 Spence JD. Metabolic vitamin B12 deficiency: a missed opportunity to prevent dementia and stroke. Nutr Res. 2016;36(2):109-16.

28 Bonita R, Duncan J, Truelsen T, Jackson RT, Beaglehole R. Passive smoking as well as active smoking increases the risk of acute stroke. Tob Control. 1999;8(2):156-60.
29 Reid RD, Mullen KA, Slovinec D'Angelo ME, Aitken DA, Papadakis S, Haley PM, et al Smoking cessation for hospitalized smokers: an evaluation of the "Ottawa Model". Nicotine Tob Res. 2010;12(1):11-8.

30 Epstein KA, Viscoli CM, Spence JD, Young LH, Inzucchi SE, Gorman M, et al. Smoking cessation and outcome after ischemic stroke or TIA. Neurology. 2017;89(16):1723-9.

31 Collins R, Reith C, Emberson J, Armitage J, Baigent $\mathrm{C}$, Blackwell $\mathrm{L}$, et al. Interpretation of the evidence for the efficacy and safety of statin therapy. Lancet. 2016;388(10059): 2532-61.

32 Amarenco P, Goldstein LB, Szarek M, Sillesen $\mathrm{H}$, Rudolph AE, Callahan A III, et al. Effects of intense low-density lipoprotein cholesterol reduction in patients with stroke or transient ischemic attack: the Stroke Prevention by Aggressive Reduction in Cholesterol Levels (SPARCL) trial. Stroke. 2007;38(12):3198204.

33 Szarek M, Amarenco P, Callahan A, DeMicco D, Fayyad R, Goldstein LB, et al. Atorvastatin reduces first and subsequent vascular events across vascular territories: the SPARCL trial. J Am Coll Cardiol. 2020;75(17):2110-8.

34 Mortensen MB, Nordestgaard BG. Elevated LDL cholesterol and increased risk of myocardial infarction and atherosclerotic cardiovascular disease in individuals aged 70100 years: a contemporary primary prevention cohort. Lancet. 2020;396(10263): 1644-52.

35 Ouchi Y, Sasaki J, Arai H, Yokote K, Harada K, Katayama Y, et al. Ezetimibe lipid-lowering trial on prevention of atherosclerotic cardiovascular disease in 75 or older (EWTOPIA 75): a randomized, controlled trial. Circulation. 2019;140(12):992-1003.

36 Bohula EA, Wiviott SD, Giugliano RP, Blazing MA, Park JG, Murphy SA, et al. Prevention of stroke with the addition of ezetimibe to statin therapy in patients with acute coronary syndrome in IMPROVE-IT (Improved Reduction of Outcomes: Vytorin Efficacy International Trial). Circulation. 2017;136(25): 2440-50.

37 Mach F, Baigent C, Catapano AL, Koskinas KC, Casula M, Badimon L, et al. 2019 ESC/ EAS Guidelines for the management of dyslipidaemias: lipid modification to reduce cardiovascular risk: the Task Force for the management of dyslipidaemias of the European Society of Cardiology (ESC) and European Atherosclerosis Society (EAS). Eur Heart J. 2020 Jan 1;41(1):111-88

38 Bass MJ, McWhinney IR, Donner A. Do family physicians need medical assistants to detect and manage hypertension? CMAJ. 1986; 134(11):1247-55.

39 Birkett NJ, Donner AP, Maynard M. Prevalence and control of hypertension in an Ontario county. Can Med Assoc J. 1985;132(9): 1019-24. 
40 Spence JD. Antihypertensive drugs and prevention of atherosclerotic stroke. Stroke. 1986;17(5):808-10.

41 Spence JD. Physiologic tailoring of therapy for resistant hypertension: 20 years' experience with stimulated renin profiling. Am J Hypertens. 1999;12(11 Pt 1):1077-83.

42 Li C, Engström G, Hedblad B, Berglund G, Janzon L. Blood pressure control and risk of stroke: a population-based prospective cohort study. Stroke. 2005;36(4):725-30.

43 Haynes RB, Taylor DW, Sackett DL, Gibson ES, Bernholz CD, Mukherjee J. Can simple clinical measurements detect patient noncompliance? Hypertension. 1980;2(6):757-64.

44 Spence JD. Controlling resistant hypertension. Stroke Vasc Neurol. 2018;3(2):69-75.

45 Juraschek SP, Miller ER 3rd, Weaver CM, Appel LJ. Effects of sodium reduction and the DASH diet in relation to baseline blood pressure. J Am Coll Cardiol. 2017;70(23):2841-8.

46 Wong DG, Spence JD, Lamki L, Freeman D, McDonald JW. Effect of non-steroidal antiinflammatory drugs on control of hypertension by beta-blockers and diuretics. Lancet. 1986;1(8488):997-1001.

47 Spence JD. Hypertension in Africa. Eur J Prev Cardiol. 2019;26(5):455-7.

48 Jones ES, Spence JD, McIntyre AD, Nondi J, Gogo K, Akintunde A, et al. High frequency of variants of candidate genes in black Africans with low renin-resistant hypertension. Am J Hypertens. 2017;30(5):478-83.

49 Akintunde A, Nondi J, Gogo K, Jones ESW, Rayner BL, Hackam DG, et al. Physiological phenotyping for personalized therapy of uncontrolled hypertension in Africa. Am J Hypertens. 2017;30(9):923-30.

50 Spence JD. Individualized therapy for hypertension. Hypertension. 2006;47(3):e11.

51 Cohen JB, Cohen DL, Herman DS, Leppert JT, Byrd JB, Bhalla V. Testing for primary aldosteronism and mineralocorticoid receptor antagonist use among U.S. veterans: a retrospective cohort study. Ann Intern Med. 2021 Mar;174(3):289-97.

52 Brown JM, Siddiqui M, Calhoun DA, Carey RM, Hopkins PN, Williams GH, et al. The unrecognized prevalence of primary aldosteronism: a cross-sectional study. Ann Intern Med. 2020;173(1):10-20.

53 Spence JD. Blind spots in the new International Society of Hypertension guidelines: physiologically individualized therapy for resistant hypertension based on renin/aldosterone phenotyping, and amiloride for Liddle phenotype. J Hypertens. 2020;38(11):2338.

54 McEvoy JW, Chen Y, Rawlings A, Hoogeveen RC, Ballantyne CM, Blumenthal RS, et al. Diastolic blood pressure, subclinical myocardial damage, and cardiac events: implications for blood pressure control. J Am Coll Cardiol. 2016;68(16):1713-22.

55 Park JH, Ovbiagele B. Post-stroke diastolic blood pressure and risk of recurrent vascular events. Eur J Neurol. 2017;24(11):141623.
56 Spence JD. Risk from low blood pressure in frail older adults: diastolic pressure and pulse pressure are important. Age Ageing. 2020 Jun 10:afaa084.

57 Blanco PJ, Müller LO, Spence JD. Blood pressure gradients in cerebral arteries: a clue to pathogenesis of cerebral small vessel disease. Stroke Vasc Neurol. 2017;2(3):108-17.

58 Spence JD, Sibbald WJ, Cape RD. Pseudohypertension in the elderly. Clin Sci Mol Med Suppl. 1978;4:399s-402s.

59 Burchfiel CM, Curb JD, Rodriguez BL, Abbott RD, Chiu D, Yano K. Glucose intolerance and 22-year stroke incidence. The Honolulu Heart Program. Stroke. 1994;25(5): 951-7.

60 Janghorbani M, Hu FB, Willett WC, Li TY, Manson JE, Logroscino G, et al. Prospective study of type 1 and type 2 diabetes and risk of stroke subtypes: the Nurses' Health Study. Diabetes Care. 2007;30(7):1730-5.

61 Ripamonti E, Azoulay L, Abrahamowicz M, Platt RW, Suissa S. A systematic review of observational studies of the association between pioglitazone use and bladder cancer. Diabet Med. 2019;36(1):22-35.

62 Pantoni L. Potential new horizons for the prevention of cerebrovascular diseases and dementia. JAMA Neurol. 2019;76(5):521-2.

63 Sheiner LB, Rubin DB. Intention-to-treat analysis and the goals of clinical trials. Clin Pharmacol Ther. 1995;57(1):6-15.

64 Kernan WN, Viscoli CM, Furie KL, Young LH, Inzucchi SE, Gorman M, et al. Pioglitazone after ischemic stroke or transient ischemic attack. N Engl J Med. 2016;374(14):1321-31.

65 Wilcox R, Bousser MG, Betteridge DJ, Schernthaner G, Pirags V, Kupfer S, et al. Effects of pioglitazone in patients with type 2 diabetes with or without previous stroke: results from PROactive (PROspective pioglitAzone Clinical Trial In macroVascular Events 04). Stroke. 2007;38(3):865-73.

66 Lee M, Saver JL, Liao HW, Lin CH, Ovbiagele B. Pioglitazone for secondary stroke prevention: a systematic review and meta-analysis. Stroke. 2017;48(2):388-93.

67 Spence JD, Viscoli CM, Inzucchi SE, Dearborn-Tomazos J, Ford GA, Gorman M, et al. Pioglitazone therapy in patients with stroke and prediabetes: a post hoc analysis of the IRIS randomized clinical trial. JAMA Neurol. 2019;76(5):526-35.

68 Rajagopalan S, Dutta P, Hota D, Bhansali A, Srinivasan A, Chakrabarti A. Effect of low dose pioglitazone on glycemic control and insulin resistance in Type 2 diabetes: a randomized, double blind, clinical trial. Diabetes Res Clin Pract. 2015;109(3):e32-5.

69 Adachi H, Katsuyama H, Yanai H. The low dose $(7.5 \mathrm{mg} /$ day) pioglitazone is beneficial to the improvement in metabolic parameters without weight gain and an increase of risk for heart failure. Int J Cardiol. 2017;227:2478.

70 Gent M, Barnett HJ, Sackett DL, Taylor DW. A randomized trial of aspirin and sulfinpyr- azone in patients with threatened stroke. Results and methodologic issues. Circulation. 1980;62(6 Pt 2):V97-105.

71 Wang Y, Zhao X, Lin J, Li H, Johnston SC, Lin Y, et al. Association between CYP2C19 loss-of-function allele status and efficacy of clopidogrel for risk reduction among patients with minor stroke or transient ischemic attack. JAMA. 2016;316(1): $70-8$.

72 Jneid H. Ticagrelor or prasugrel in acute coronary syndromes: the winner takes it all? $\mathrm{N}$ Engl J Med. 2019;381(16):1582-5.

73 Grosser T, Fries S, Lawson JA, Kapoor SC, Grant GR, FitzGerald GA. Drug resistance and pseudoresistance: an unintended consequence of enteric coating aspirin. Circulation. 2013;127(3):377-85.

74 Bhatt DL, Grosser T, Dong JF, Logan D, Jeske W, Angiolillo DJ, et al. Enteric coating and aspirin nonresponsiveness in patients with type 2 diabetes mellitus. J Am Coll Cardiol. 2017;69(6):603-12.

75 Hackam DG, Spence JD. Antiplatelet therapy in ischemic stroke and transient ischemic attack. Stroke. 2019;50(3):773-8.

76 Deykin D. Thrombogenesis. N Engl J Med. 1967;276(11):622-8.

77 Caplan LR, Fisher M. The endothelium, platelets, and brain ischemia. Rev Neurol Dis. 2007;4(3):113-21.

78 Connolly SJ, Eikelboom J, Joyner C, Diener HC, Hart R, Golitsyn S, et al. Apixaban in patients with atrial fibrillation. $\mathrm{N}$ Engl J Med. 2011;364(9):806-17.

79 Weitz JI, Lensing AWA, Prins MH, Bauersachs R, Beyer-Westendorf J, Bounameaux H, et al. Rivaroxaban or aspirin for extended treatment of venous thromboembolism. N Engl J Med. 2017;376(13):1211-22.

80 Spence JD. Anticoagulation in patients with embolic stroke of unknown source. Int J Stroke. 2019;14(4):334-6.

81 Connolly SJ, Eikelboom JW, Ng J, Hirsh J, Yusuf S, Pogue J, et al. Net clinical benefit of adding clopidogrel to aspirin therapy in patients with atrial fibrillation for whom vitamin $\mathrm{K}$ antagonists are unsuitable. Ann Intern Med. 2011;155(9):579-86.

82 Hart RG, Sharma M, Mundl H, Kasner SE, Bangdiwala SI, Berkowitz SD, et al. Rivaroxaban for stroke prevention after embolic stroke of undetermined source. N Engl J Med. 2018; 378(23):2191-201.

83 Diener HC, Sacco RL, Easton JD, Granger CB, Bernstein RA, Uchiyama S, et al. Dabigatran for prevention of stroke after embolic stroke of undetermined source. N Engl J Med. 2019; 380(20):1906-17.

84 Bogiatzi C, Wannarong T, McLeod AI, Heisel M, Hackam D, Spence JD. SPARKLE (Subtypes of Ischaemic Stroke Classification System), incorporating measurement of carotid plaque burden: a new validated tool for the classification of ischemic stroke subtypes. Neuroepidemiology. 2014;42(4):24351. 
85 Zhang H, Li Z, Dai Y, Guo E, Zhang C, Wang $\mathrm{Y}$. Ischaemic stroke etiological classification system: the agreement analysis of CISS, SPARKLE and TOAST. Stroke Vasc Neurol. 2019;4(3):123-8.

86 Kasner SE, Swaminathan B, Lavados P, Sharma M, Muir K, Veltkamp R, et al. Rivaroxaban or aspirin for patent foramen ovale and embolic stroke of undetermined source: a prespecified subgroup analysis from the NAVIGATE ESUS trial. Lancet Neurol. 2018; 17(12):1053-60.

87 Man-Son-Hing M, Nichol G, Lau A, Laupacis A. Choosing antithrombotic therapy for elderly patients with atrial fibrillation who are at risk for falls. Arch Intern Med. 1999;159(7):677-85.

88 Spence JD. Stroke: atrial fibrillation, stroke prevention therapy and aging. Nat Rev Cardiol. 2009;6(7):448-50.

89 van Walraven C, Hart RG, Connolly S, Austin PC, Mant J, Hobbs FD, et al. Effect of age on stroke prevention therapy in patients with atrial fibrillation: the atrial fibrillation investigators. Stroke. 2009;40(4):1410-6.
90 Fralick M, Colacci M, Schneeweiss S, Huybrechts KF, Lin KJ, Gagne JJ. Effectiveness and safety of apixaban compared with rivaroxaban for patients with atrial fibrillation in routine practice: a cohort study. Ann Intern Med. 2020 Apr 7;172(7):463-73.

91 Reilly PA, Lehr T, Haertter S, Connolly SJ, Yusuf S, Eikelboom JW, et al. The effect of dabigatran plasma concentrations and patient characteristics on the frequency of ischemic stroke and major bleeding in atrial fibrillation patients: the RE-LY Trial (Randomized Evaluation of Long-Term Anticoagulation Therapy). J Am Coll Cardiol. 2014;63(4):3218.

92 Naylor AR. Time to rethink management strategies in asymptomatic carotid artery disease. Nat Rev Cardiol. 2012;9(2):116-24.

93 Spence JD, Coates V, Li H, Tamayo A, Muñoz C, Hackam DG, et al. Effects of intensive medical therapy on microemboli and cardiovascular risk in asymptomatic carotid stenosis. Arch Neurol. 2010;67(2):180-6.

94 Howard DPJ, Gaziano L, Rothwell PM, Oxford Vascular S. Risk of stroke in relation to degree of asymptomatic carotid stenosis: a population-based cohort study, systematic review, and meta-analysis. Lancet Neurol. 2021; 20(3):193-202.
95 Spence JD. Treatment of asymptomatic carotid stenosis. Lancet Neurol. 2021;20(3):163-5.

96 Paraskevas KI, Veith FJ, Spence JD. How to identify which patients with asymptomatic carotid stenosis could benefit from endarterectomy or stenting. Stroke Vasc Neurol. 2018; 3(2): $92-100$.

97 Naylor AR, Ricco JB, de Borst GJ, Debus S, de Haro J, Halliday A, et al. Editor's choice: management of atherosclerotic carotid and vertebral artery disease: 2017 clinical practice guidelines of the European Society for Vascular Surgery (ESVS). Eur J Vasc Endovasc Surg. 2018;55(1):3-81.

98 Almekhlafi MA, Demchuk AM, Mishra S, Bal S, Menon BK, Wiebe S, et al. Malignant emboli on transcranial Doppler during carotid stenting predict postprocedure diffusionweighted imaging lesions. Stroke. 2013;44(5): 1317-22.

99 Spence JD. Periprocedural events dominate outcomes of carotid stenting and endarterectomy. Lancet Neurol. 2019;18(4):321-2. 